\title{
Correction to: Antioxidant activity, polyphenolic contents and essential oil composition of aniseed (Pimpinella anisum L.) as influenced by 5 -aminolevulinic acid
}

Vahid Tavallali $^{1} \cdot$ Faraneh Zareiyan ${ }^{2}$

Published online: 22 September 2020

๑) Springer Science+Business Media, LLC, part of Springer Nature 2020
Publisher's Note Springer Nature remains neutral with regard to jurisdictional claims in published maps and institutional affiliations.

The first sentence of Plant materials and treatments section under Materials and Methods should be "A greenhouse trial was conducted at Shiraz, Iran" instead of "A greenhouse trial was conducted at the Shiraz Payame Noor University situated in Golestan town $\left(29^{\circ} 36^{\prime} \mathrm{N}\right.$ and $52^{\circ} 32^{\prime} \mathrm{E}, 1490 \mathrm{~m}$ above sea level)".

The original article can be found online at https://doi.org/10.1007/ s11694-018-9722-7.

Vahid Tavallali

vtavallali@gmail.com

1 Department of Agriculture, Payame Noor University (PNU), P.O. Box 19395-3697, Tehran, Iran

2 Department of Natural Resources, Fars Agricultural and Natural Resources Research and Education Center, AREEO, Shiraz, Iran 